\title{
„RODZINNA” FORMA KLASZTORÓW PODWÓJNYCH W HISZPANII
}

Wíród róznych sposobów urzeczywistniania ideazów życia chrześc1jarisklego w nurcie monastycyzmu, na specjalnz uwag̨ zasługują tzw. "klasztory podwójne". Obok wczesnochrześcijańsklego stylityzmu, czy środnjowtecznych zakonów rycerskich stanowiq one ciekawa $i$ właściwie przobrziniała strukturę organizacji życia klasztornego. Istniały równolegle do uznanych 1 historycznie sprawdzonych wspólnot zakonnych wyłącznie męskich lub wyłącznie żeńskich. Względy praktyczne, a zwaszcza realne niebezpleczeristwo naducyć, zwizzane z idea koascezy, zadecydowały, ze klasztory podwójne zanikajaz w Kościele Wsciodntm w IX w.; w Kościele Zachodnim zaś po kryzysie w wiekach VIII-X, pojawlajt sie jeszcze na przecigg czterech stuleci; najdzuzej - bo do XVI w. przetrwały w obrzadku aronickin na teronie Libanu.

\section{Problem definicji}

Poindo, ze forma klasztorów podwójnych w ogólnych zarysach jost ativo wyróznlalna /stanowi ją wspólne zanjeszkiwanie zakonnjków 1 zakonnic, podporządkoranych jednemu przełożonemu/, to jednak kwostia ścisłej definicji opisujzzej różorodność praktyki zycia takich klasztorów pozostajo nadal otwarta. Według S.IIIfischa klasztory podwójne w sonjie waściwym istniejz wórczas, gdy zachodz1 Jodność lokalna 1 prawnamichów 1 iniszek ${ }^{1}$. Dla C.Goslstona "jednośs lokalna" oznacza w praktyce "wspólny budynok zanleszlivany przoz wspólnotę męskil l zeníską" "2 do pozostałych elementów konsty-

1 Dizlonario dogld Ist1tuti di perfezlone VI, 51: "monasteri nei quali vivono monacl a tuonache, sicché 11 cosplesso venga a costitulre una unita locale e glurldica".

2 The Cathollc Lncyclopeila, New York 1913, t.10,452: "Monasteries Doublo religious houses coiprising condunitios op both men and women /.../ unftad under tho rule of one superior, and using one church in common for tieir liturglcal offices". 
tuuj zcych interesujłciz nas forme zycia klasztornego zalicza on:

a. wspólną regułe

b. posiadanie irspólnego przełożonego

c. wspólne sprawowanio liturgil w tej samoj świ iztyni ${ }^{3}$.

Nieco szerzej jeuność lokalnz pojmuje li.Leclercq, który skłonny jest uznawać za klasztory podwójne takie, które skupiaja w obrębie jednego ogrodzenia osoby obu płc1 ${ }^{4}$. Podobnie zdaje sie określaó je G.F.Schwartzenberg, który jakkolwiek nie precyzuje sposobu rozumienia jedności lokalnej, to jednak uważa, ze każda jef forma jest wystarczaj zca dla uznania klasztoru za podwójny, tym bardziej gdy dotyczy tego samego zakonu ${ }^{5}$. Jeszcze dalej idzle Ph.schoitz, który pojmuje jedność lokalną jako bliskość dwóch oddzielonych budynkótw, zamleszkiwanych przez wspólnotę michóm 1 odrębnq wspólnote mntszek ${ }^{6}$. Ponadto, jako cechę wyróziniającá podaje on wspólne użytkowante dóbr przez obie wspólnoty klasztoru podwójnego, pozostajazee pod jednym przełożonym.

Ogólnie więc można zdefiniować klasztor podwójny jako wspólnote mnichów 1 inniszek, pozostajazca pod posłuszeństwem jedneriu przełożonemu, zamleszkująca bąd́ to ten sam budynek, baqdź budynk1 bl1sko sleble położone, korzystającaz ze wspólnych dóbr 1 wspólnte sprawujace liturgie.

2. IIstoryczna praktyka klasztorów podwójnych

Jezell przyjmie sie rozszerzonz dellnicje klasztorów podwójnych, uwzględniającą pewną bliskość klasztoru męskiego 1 zeńskie-

\section{Jak wyzej.}

4 DACL 11,2182: "monastères qui abritaient dans uno même encelnte des personnes des deux sexes".

5 G.F.Schwartzenberg, Groot placcaet - en charterboek van Vriesland, Leeuwarden 1768-1793, t.1, 249: "Voor een dubbelklooster in den oingenlijken zin Wordt verelscht de localo en juridische eonieid van een mannen on een vrouwencommunitelt die tot dezelide orde behooven".

6 Ph.Schmitz, I1stoire de l'ordre de salnt Benolt, Maredsous $1948^{2}$. $t .1,322$ : "on entend par monastères dubles, doux malsons, toutes voleines, qui matériellement sont strictement separós mais dont 
go, to początków tej formy monastycyzmu można stę dopatrzeć juź u zarania życia zakonnego w chrześcjjaństwie. Znane sa bowiem powszochnte fakty lstnienia blisko stebie męskiej wspólnoty cenobitycznej św.Pachomiusza 1 wspólnoty żeńskiej, kiorowanej przez jego siostre; obie były położone w okolicach Tabennisi. Podobne zwiazki zachodzlły między wspólnotą klerowana przez św.Bazylogo i św.Makrynę. Względy bowiem religijne 1 ekonomiczne skłaniały do laczenia się w większe organtzmy klasztorne, by tą drogą zapewnić kierownictwo duchowe, posługe sakramental naz a nierzadko i bezpleczeństwo wspólnocle zeńskiej 1 jednooześnie uzyskać pomoc w sprawach natury gospodarczej 1 bytowej. Z terenu Egiptu, gdzio upatruje się początków tej formy monastycyzmu chrześcijarískiego, przenosi się ona do Ita$111^{\top} 1$ Gal11, skąd promientuje na teren Półwyspu Iberyjskiego (w VII พ. 8200 klasztorón), do Angl1: ${ }^{9}$ i na teren dzisiejszej Belgli 1 Holand $11^{10}$. Jest rzecz znamienną, ze poza klasztorem w Heidenheim forma ta nie przyjęa sie na terenie Niemiec.

Wspólne zamieszkirante $i$ częste kontakty muichów 1 mniszek z klasztorów podwójnych stawały się coraz częściej przedmiotem krytyk1, kt6ra z czasem przerodziła sie w restrykcje prawne. W pierwszej połowie VI w. cesarz Justynian dwukrotnie wypowiedział sie przeciw tej formie monastycyzmu 11 opowiadając się zdecydowanie za

I une est habitée par des molnes et l'autre par des monialesn.

7 Istniente klasztoru podwójnego na Sardynif potwierdza papiez Grzegorz Wielki/Epistola XLVIII, PL 77,511-512, tłum. J.Czuj, Sw. Grzegorz - Listy, Warszawa 1954, t.1,86/, Rzymie zaś Beda Wiolebny /Historla eoclesiastica IV, 1, PL 95,172/.

8 D.Yepes, Chronicon Generale Ordinis S.P.N.Benodicti, Cologne 1603.

9 Przed inwazja duńska w IX w. istniały tu klasztory podwójno w Wimborne 1 Barking. Późnlej do bardziej znanych na tym terenie nalożay klasztory śr.Hildy whitby, założony przez św.Aidana oraz w Coldinghain, Ely, Shoopey 1 Minstor.

10 Klasztory podwójne na tym terenie powstają w okresie średniowlocznego odnowlenta ich galijskiego modelu. A.Arts /Het dubbelkloster Dikninge, Assen 1945, 36-37/ podajizc lokalizacje tych klasztorów wymienla: Oostbrook, Weersolo, Monteriolde /1247/, Foldwerd, Selword $/ 1318 /$, Stavoron, Foswerd $/ 1390 /$.

11 Cod. I,III, $43 / 529 \mathrm{r.} /$; Nov. CXXIII, $36 / 546 \mathrm{r.} /$. 
oddzielenicr obu wspólnot. Z pewnościa rozporzadzenia cesarskie nto zostały wykonane, skoro diva i póz wieku pózniej Sobór Nicejski II /787/ ponownie zakazał ich zakładania tytułem możliwego skandalu 1 zgorszenta ${ }^{12}$. Jednakże dopiero zdecydowana postawa $i$ energiczne działanła reformatorów, skupionych woisóz Teodora Studyty /zm. 826/ oraz patriarchy Nicefora I /806-814/, połozyły kres klasztorom podwójnym w Bizancjum.

Można przypuszczać, że w ostatnim okresio ich istnienia na Wschodzie jodnyri $\mathrm{z}$ motywór decydujących o powstaniu były decyzje całych rodzin o podjectu stylu życia monastycznego. Wskazuje na to wyraźnie uzyte przez Sobór Nicejski II sformułoranie: "Si qui autem volunt $c u$ is $c$ o g $n$ a $t i s$ mundo renuntiare et vitam soqui monasticar..." Motyw ten nalezy uznać za charakterystyczny równleż dia monastycyzmu iberyjskiego w okrosie wizygockiego rozkwitu od VI do VIII w.

Funiccje przełozonego $w$ tych klasztorach sprawowały często koblety, zwaszcza na terenie Anglil i pin. Gal1i, gdzio posiadały one tytuł opatki båź przeoryszy. Praktykę tę uzasadniano często biblijnym poleconiem Chrystusa: "Niewiasto, oto Syn twój" /J 19,26/. Mięczy innymi z tej Inspiracji powstazy w Gali1 we wczesnyin średniowieczu takıe klasztory z żeńskim przeźożonym, jak: Fontovrault /1099/, Bridgettinos $/ 1346 /$, a $w$ Anglil klasztor św.H1ldy w Whitby czy siv. Etheldreda w Lly. Uznawano bowier, ze macierzyństmo posiada autorytet $z$ samej natury, podezas gay ojcostwo ma raczej charakter lemalny. 17 praktyce zycia stosowano te sama reguze da mnichów i mniszek. Poczatkowo wykorzystywano ogólne wskazania zawarte w Regułach św.Bazylego ${ }^{13}$. W klasztorach polwójnych na teronie Hiszpaní największa

12 Canones Synodi Nicaenae II, can. 20, Mans1 XIII, 755: "A praesonti statuimus non fieri duplex monastorium, quoniam hoc fit multis scandalun et opfensio. Si qui auter volunt cum cognatis mundo renuntiare et vitan segui monasticam, viros quiden oportet in virorum monasteria discedere; Paeminas autem ingred1 in mulierum monasteria: hoc enim est jeoacceptum. Quae autom huc usque duplicia fuerunt, serventur sccundum canonern sancti patris nostri Basilii et secundum eius constitutionem ita regantur. In uno autem monasterio no vorsentur monach1 et monachae".

13 Regulae fusius tractatae; legulae brevius tractatae 108-111,154223 , PG 31,853-1052, 1156-1157, 1184-1229. 
popularnośc1ą cieszyła sie przyplsywana św.Fruktuozow1 z Bragi "Reguła zycia wspólnego"14. W drugim okresie rozwoju tego typu monastyoyzmu posługiwano 818 zasadani 1 regułani przyjętym $w$ klasztorach benedyktyriskich, premonstrateriskich, kamedulskich bądź august1ańskich. Na przykład $w$ znanym klasztorzo podiófnym w Fontevrault, ostro zwalczanym pod wpływem Petrondl1 z Craon Chemille, drugiej z kolel opatk1, przez bpa Reuna 1 opata z Vendôme, wspólnota zeńska przyjeła reguze św.Benedykta. Po poczlale zaś tego klasztoru wspólnota męska kierowała się reguła św. Augustyna.

\section{H1szpanskie klasztory rodzinne}

Wzrastające zagrozenie najazdem Wizygotów a potem lch okupacja od VI-VIII w., a następnie zagrozenie 1 inwazja Arabów, powodowały społeczny ruoh konsolidacjl obronnej w Hiszpanil. Przybrat on m.in. forine klasztorói podwófnych, ugruntorane jeszcze mocntej w wyntku polityki podatkowej zalnicjowanej przez wadce wizygookiego rekkareda /586-601/, który 589 r. porzuciwszy arianizm przeszedz na katolicyza. Zivalniat on wspólnoty klasztorne od świadczén, co w znacznej mierze stanowizo atrakcyjny motyw zakładania wspólnot klasztornych. W szybkim czasie $1 \mathrm{ch} 11 \mathrm{czba}$ zaczęza rosnąc w wyniku podejmowania przoz calo rodziny, wraz zo słuzba 1 niewolntkami monastycznogo trybu zyola. Wokól załozonogo lub przejętego kośo1oła, jako centralnego punktu liturgicznego zycia wepólnoty skuplały się pojedyncze rodziny lub kilka bliskich soble społecznośct; początkowo nie kierowały siq zadni spisana reguza. Poniewaz historla milczy o postaciaoh odznaczających sie wybltna świetościa czy talentem monastycznym, mozna witplć o lch wysokim poziomle zycla ascotycznogo, tym bardziej, ze przy braku odpowiednlego kierownictwa duchowego łatwo bylo o rażice przykłady naruszania zasad zakonnych. A.Bobor zwraca nawet uwage, zo wielo z tych klasztoró, zrzeszająych niekiedy takze kapłanów, trudnito sie grabieza 1 rozbojem ${ }^{15}$.

14 Regula comaun1s, PL 87, 1111-1127.

15 A.Bobor, Antolog1a patrystyczna, Kraków 1965, 360-361. 
Dlatego tez reforma zycia monastycznego Hiszpani1 zainicjowana przez św. Fruktuoza z Bragl zmierzała min. do kodyelkaoj1 ustawodawstwa zakonnego, które mogłoby siq stać mocna podstawa dia odnowlonyoh form organizacj1 klasztorów. Obok wspomntanej juz reguły 6́.Bazylego duza pomoo stanowiły postanowienta reglonalnych synodów opatów, przyponinające do peirnego stopnia wopółczesne kapituły generalne zakonów. Efektem 1ch obrad były m.1n. spisane reguky życia monastycznogo, spośród których najwiçkszym uznaniem eleszyła s1e tzw. "I Reguła sw.0jców", spisana podczas zgromadzenia 38 opatów 16 oraz jej modyf1kacje: "Reguła II"17 i "Reguła III"18. Duza popularnośc1a cieszyła się równiez tzw. "Uzgodniona reguła zakonnan19. Obok tych postanowień, źródeł ustawodawstwa monastyoznego na terento H1szpanif $w$ VI-VII $w$. nalezy upatrywać takze postanowientach prawnch, zawartych juz $w$ Kodeksio Teodozjusza /zebranych $w$ Lex Romana Visigothorum/, w Novellach Justyniana, wielicznych dekretełach papiedy dołączanych do zbjorów kanontcznych/np. Collectlo canonum Hispana/ oraz w postanowientach soborów powszechnych ${ }^{20}$ synodón lokalnych ${ }^{21}$.

oryginalność reguły św. Fruktuoza, przypominajacej swa surowó́cia zasady monastycyzmu irlandzkiego, pologa na tzw. "pactumn, ozy11 rodzaju umowy zawioranej miedzy mnlchem ozy mnlezka a opatem, Okrob́la ona prawa 1 obowlazk1 kazdej ze stron ${ }^{22}$. A.Mund 6 my awa przypuozczonie, zo 1dea "pactum" wywodz1 sie zo środowiska germańsk10go 1 zo-

16 Regula Sanctorum Patrum Sorapionis, Macar11, Paphnuti1 ot Alterius Macar11, PL 103,435-442.

17 Altera Patrum Regula ad monachos, PL 103,441-444.

18 Tertia Patrum Regula ad monachos, $P L$ 103,443-446.

19 Regula consensorla monachorum, PL 66, 993-996.

20 Por. Statuta Synodi Chalcedonens1s, canones: $4,6,7,8,16,18,23,24$, Mans1 VI, 1226-1230/ pośwlęcone problematyce zyola monastycznego.

21 Za najwazniejsze dla hiszpanskiego ustawodawstwa zakonnego nal zy uznac m.1n. eynody w: Elvirze / ok $300 \mathrm{r} . /$, Tarragonie $/ 516 \mathrm{r} / \mathrm{s}$ Toledo II $/ 527 \mathrm{r} . /$, Walonej $1 / 546 \mathrm{r} . /$. Saragossie II $/ 592 \mathrm{r} . /$ 1 Barcelonie $/ 599 \dot{\mathrm{r}} . /$. Pur. A.Mund 6 , Il monachesimo nella penisola lberica fino al sec. VII, w: Il monachesimo nell alto modioevo - la formazione della civiltà occidentale, Spoleto 1957, 97-108.

22 Bibliograf1e zob. G.Bardy, Cathol101smo, Par18 1956,t.4, 1655-1656: M.C.Diaz y Diaz: Index scriptorum latinorum medil aevi hispanorum, Madrid 1959, n. 216-219,245-247,314-315,317,384; J.P०r*z de Úrbel, Los monjes españoles en la edad media, Madrid 1933, t. L, 377-450; J.Herwegon, Das Paotum des hl.Fruktuosus von Braga.Kirchon- 
staka przeniesiona do IIfszpanil przez Wizygotów 23 , jakkolwiek samo pojęc1e funkcjonowało " problematyce zakonnej tego regionu juz przed IV w. 1 przetrwało $z$ pewnościz do $X$ w. 24

Zreformowane przez św. Fruktuoza klasztory rodzinne posiadały wyraźnto wydzielone 1 rozgrantezono wspólnoty męska 1 żeński, żyace pod wspólnym przełożonym. Spełniało to podstawowe wymaganta, aby uznawać je za klasztor podwójny. Taki charakter miał, np. klasztor Complutum koło $\Lambda$ storga, dla którego przodo wszystkim zostaza napisana "Regula communis". Wyróżniał się on zdecydowante od Innych klasztorów rodzinnych, zalkładanych "ob metumgehennae" lub klasztorów, w skład których mohodzili kapłani pragnący ta drogaz utrzymać lub nawet powiększyé swój stan posiadania. Wszystkte ono sq $\mathbf{q}$ ocente siv. Fruktuoza obarozone symptomami herezj1 1 schizmy 1 godza w czyste zasady życia zalsonnego 25.

rechtl1che Abhandlungen hrsg. von U.Stutz, Stuttgart 1907; tekst Pactum: PL 87,1127-1130.

23 A.Mundó, art.cyt. 103.

24 Por. kanon 13 Synodu w Elwirze /ok. $300 \mathrm{r} . /$, który inówi o "pactum virginitatis" w odniesieniu do kobiet żjacyoh zgodnio z ewangelicznz rada czyetości; por. tez: J.Bishko, Salvus of Albeldaand frontier monasticism in tenth-century Navarre. "Speculur" 23/1948/559-590; J.Orlandis, Los monastorios famillares on España durante la alta edad media, "Anuario de histor1a del derecho español" 26/1956/5-46; U.Berlière, Les monastóres doubles aux XII et XIIIe siècles. "Mémoires" publiés par I Académie royale de Belgique. Classe des lettres II ser. $18 / 1924 /$;.Bateson, Origin and early history of double Monasteries, "Transactions of the Roycl Historlcal Society", New Sories 13/1899/137-198. Szereg paralel1 moźna w yprowadzić ze wschodnia forwa klasztorów podwójnych, omówioną przez J Pargolro, Les monastéres doubles chez ios Byzantins, "Echos d"Orlent" 9/1906/21-25.

25 Por. llegula communis 1, PL 103,7430: "Solentenim nonnull1 ob metum gehennise in suis sibl domibus monastoria oomponere, et cum uxoribus, filise et servis atque vicinis curn sacramenti conditione in unum so copulare, et in suls sibl, ut diximus, vill1s ex nomine thartyrum occlesias consecrare et oas falso nomino inonasteria nuncupare". 
Klasztory rodzinne moga więc być uznawane za jedon z rodzajíw klasztorów podwójnych. Nio doprowadzily one do zaistnienia wyránegro, znaczįego środowiska ascetycznego. Fakt, zo powrócono do tej formy w Kośclele zachodnim w okresie XI-XIV w. należy wiazać barizlej z ewolucja wernętrzną zakonów, w Konie których klasztory to powstawały, niz z ewentualnyin wartośctani samej idel ko-ascezy. Otwartiz kostia pozostajo tendencja do wiqzania zeńskich odłanów nowo powstających w éredniowieczu zakonów z modelern klasztorów poưójnych.

\section{Karol Klauza - Lublin}

\section{DE MONASTERIOIUM DUPLICIUM IIISPANIAE "FaAILIAII " FOILA /Suminariun/}

Duplieia monasteria pure historicum valorem in christianorum traditione monastica habere censetur. Ut autem oorum variae pormae bone cognoscantur, recte notio "cohabitationis" Intelligenda est. Nomulli onla unain dolum, alif autew monasteria vicina utriusque sexus uti principalia elementa elushodi vitae putant. Ex eorum Pamillari forma saeculis VI-VIII praocipue in lispania plorenti, cuius poculiare olementum sine dubio "pactum" Invenitur, hypothesis dodicltur, quod etiam divisio ordinun modiaevaliua suam originen in litusmoli monasteris habet. 